\title{
Where Does the Irrigation Water Go? An Estimate of the Contribution of Irrigation to Precipitation Using MERRA
}

\author{
JIANGFENG WEI* \\ Center for Ocean-Land-Atmosphere Studies, Calverton, Maryland \\ PAUl A. DiRMEYER \\ Department of Atmospheric, Oceanic and Earth Sciences, George Mason University, Fairfax, Virginia, and Center \\ for Ocean-Land-Atmosphere Studies, Calverton, Maryland \\ DOMINIK WISSER \\ Department of Physical Geography, Utrecht University, Utrecht, Netherlands \\ MichaEL G. BOSILOVICH \\ Global Modeling and Assimilation Office, NASA Goddard Space Flight Center, Greenbelt, Maryland \\ DAVID M. MOCKO \\ SAIC and Global Modeling and Assimilation Office, NASA Goddard Space Flight Center, Greenbelt, Maryland
}

(Manuscript received 24 May 2012, in final form 21 September 2012)

\begin{abstract}
Irrigation is an important human activity that may impact local and regional climate, but current climate model simulations and data assimilation systems generally do not explicitly include it. The European Centre for Medium-Range Weather Forecasts (ECMWF) Interim Re-Analysis (ERA-Interim) shows more irrigation signal in surface evapotranspiration (ET) than the Modern-Era Retrospective Analysis for Research and Applications (MERRA) because ERA-Interim adjusts soil moisture according to the observed surface temperature and humidity while MERRA has no explicit consideration of irrigation at the surface. But, when compared with the results from a hydrological model with detailed considerations of agriculture, the ET from both reanalyses show large deficiencies in capturing the impact of irrigation. Here, a back-trajectory method is used to estimate the contribution of irrigation to precipitation over local and surrounding regions, using MERRA with observation-based corrections and added irrigation-caused ET increase from the hydrological model. Results show substantial contributions of irrigation to precipitation over heavily irrigated regions in Asia, but the precipitation increase is much less than the ET increase over most areas, indicating that irrigation could lead to water deficits over these regions. For the same increase in ET, precipitation increases are larger over wetter areas where convection is more easily triggered, but the percentage increase in precipitation is similar for different areas. There are substantial regional differences in the patterns of irrigation impact, but, for all the studied regions, the highest percentage contribution to precipitation is over local land.
\end{abstract}

* Current affiliation: Jackson School of Geosciences, The University of Texas at Austin, Austin, Texas.

Corresponding author address: Jiangfeng Wei, Jackson School of Geosciences, The University of Texas at Austin, 2275 Speedway C9000, Austin, TX 78712.

E-mail: jwei@utexas.edu

\section{Introduction}

Irrigation is an important human activity that has the potential to impact local and regional climate through the hydrological cycle and surface energy balance (e.g., Chase et al. 1999; Pielke et al. 2011). About two-thirds of the global freshwater withdrawals from surface and underground are used for agriculture (Shiklomanov 2000),

DOI: 10.1175/JHM-D-12-079.1

(C) 2013 American Meteorological Society 
of which irrigation is the main component. Although there are still uncertainties in the amount of irrigation over various regions (Wisser et al. 2008), numerous modeling and observational studies have consistently shown that irrigation can change the surface energy partition by reducing sensible heat flux and increasing latent heat flux, thereby reducing surface temperature and the diurnal temperature range (e.g., Adegoke et al. 2003; Haddeland et al. 2006; Mahmood et al. 2006; Kueppers et al. 2007; Sacks et al. 2009; Lobell and Bonfils 2008; Ozdogan et al. 2010; Sorooshian et al. 2011). In addition to the impact on surface climate, irrigation also increases the amount of water vapor in the atmosphere through evapotranspiration (ET) (Boucher et al. 2004; Mahmood et al. 2008). The additional moisture can enhance the convective available potential energy (CAPE) within the boundary layer and make it thermodynamically more conducive to increase in rainfall (Pielke and Zeng 1989; Betts et al. 1996). These have been demonstrated by some modeling (e.g., Segal et al. 1998) and observational (e.g., Moore and Rojstaczer 2002; DeAngelis et al. 2010) studies. Negative impacts of irrigation on precipitation, which have also been found in some modeling studies, are mostly caused by a weakened monsoon circulation (e.g., Saeed et al. 2009; Douglas et al. 2009; Puma and Cook 2010; Guimberteau et al. 2012), although negative soil moisture-precipitation feedback is likely in some conditions (Findell and Eltahir 2003).

Therefore, irrigation can contribute to precipitation directly as precipitable water vapor and at the same time change the atmospheric instability, or it can impact precipitation indirectly by modifying the atmospheric circulation and moisture transport. These effects usually happen concurrently during large-scale irrigations (e.g., Saeed et al. 2009; Douglas et al. 2009; Lee et al. 2011). Observational studies cannot easily separate them, while model simulations, even if capable, are not completely reliable. As indicated by some land model intercomparison experiments (e.g., Henderson-Sellers et al. 1996; Dirmeyer et al. 2006), the response of ET to the availability of surface water is highly model dependent. Coupling land models with atmospheric models can amplify the uncertainties (Wei et al. 2010).

In this study, we use reanalysis data and estimated ET over irrigated areas to examine the direct impact of irrigation on precipitation, that is, through its contribution to precipitable water vapor and the associated impact on convective instability. A back-trajectory method is used to investigate the water vapor transport. Irrigation may substantially modify the large-scale circulations and patterns of water vapor transport, but the reanalysis data should implicitly include these changes as a result of the assimilation of meteorological observations. Therefore, we estimate the impact of irrigation on precipitation under these already-modified climate conditions, which is different from the total impact of irrigation as assessed by some model simulations (e.g., Saeed et al. 2009; Douglas et al. 2009; Lee et al. 2011; Guimberteau et al. 2012). This separates the direct impact of irrigation on precipitation from other indirect impacts.

\section{Data and method}

\section{a. Irrigation area map}

The Food and Agriculture Organization of the United Nations (FAO)/University of Frankfurt global map of irrigated areas (Siebert et al. 2005, 2007) is used to define irrigation area (Fig. 1). It reports the percentage of area equipped for irrigation around the year 2000. The original data has a resolution of $5^{\prime}\left(1 / 12^{\circ}\right)$, and Fig. 1 shows the data at $1 / 2^{\circ}$ resolution. Four intensively irrigated regions-northern India/Pakistan, the North China Plain, the California Central Valley, and the Nile Valley—are selected for specific analysis.

\section{b. Reanalysis data}

In this study, the Modern-Era Retrospective Analysis for Research and Applications (MERRA; Rienecker et al. 2011) is primarily used. MERRA was generated with the Goddard Earth Observing System (GEOS-5) atmospheric model and data assimilation system, with a particular emphasis on the hydrologic cycle. For the land variables, we use an early version of a product called "MERRA-Land" (Reichle et al. 2011) instead of the original MERRA data. MERRA-Land is more accurate than the original MERRA due to a correction to the model-generated MERRA precipitation with the observation-based Global Precipitation Climatology Project (GPCP) pentad product (Huffman et al. 2009; Xie et al. 2003) and revision of parameter values in the original canopy precipitation interception model, which caused large biases. MERRA and MERRA-Land do not consider irrigation in the land model and also do not assimilate surface observations of temperature and humidity. MERRA covers the period from 1979 to the present and MERRA-Land covers the period from 1979 to 2008 . The horizontal grid of both is $2 / 3^{\circ}$ longitude by $1 / 2^{\circ}$ latitude.

The European Centre for Medium-Range Weather Forecasts Interim Re-Analysis (ERA-Interim; Dee et al. 2011) is used for comparison with MERRA. Although ERA-Interim also does not explicitly include irrigation, it uses surface observations of temperature and humidity to update soil moisture and soil temperature estimates for each of the four layers of the land 


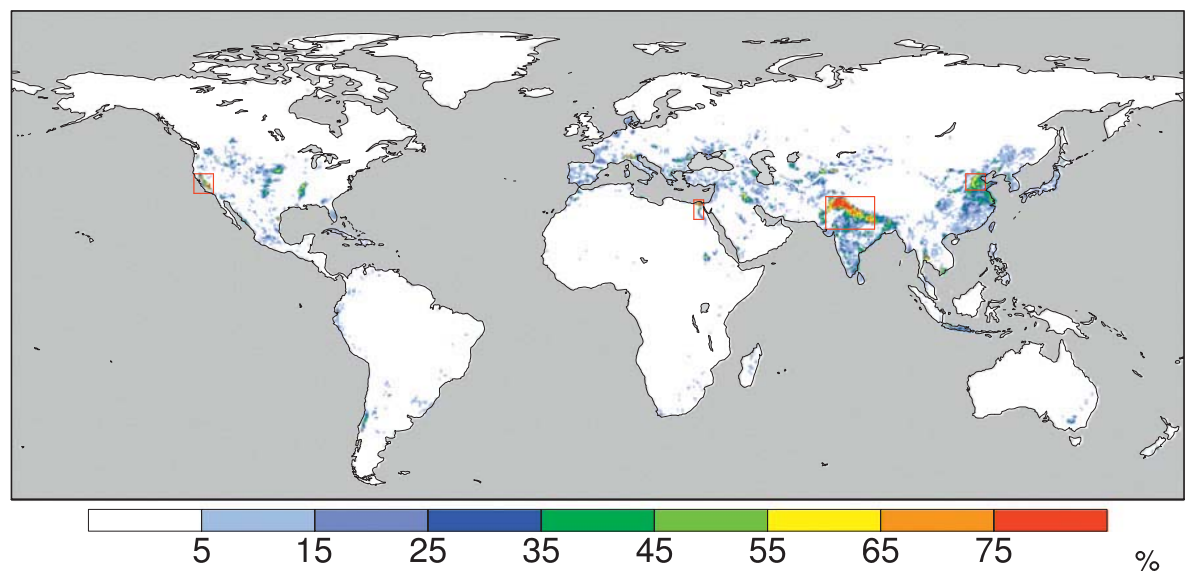

FIG. 1. The percentage of area equipped for irrigation around year 2000 from the FAO/ University of Frankfurt (Siebert et al. 2005, 2007). The four regions in the red boxes are for detailed analysis.

surface model (Douville et al. 2000; Mahfouf et al. 2000). This indirectly considers the effect of irrigation on soil moisture and ET (Tuinenburg et al. 2012). The ERA-Interim data cover the period from 1979 to 2010 and have a horizontal grid of $0.75^{\circ} \times 0.75^{\circ}$. Both MERRA and ERA-Interim are examples of a new generation of reanalysis that incorporates many important model improvements and changes in analysis methodology.

Figure 2 compares the ET from MERRA-Land and ERA-Interim over four selected irrigation regions. Each region (land points only and excluding Tibet) is separated into two halves with low and high irrigation based on the percentage of irrigated area in each grid box (shown in Fig. 1). ET over the two areas is shown separately to identify the impact of irrigation. For both MERRA and ERA-Interim, the more irrigated areas generally show higher ET than the less irrigated areas, even though there is no explicit irrigation in MERRA. (Note that there may be natural climate differences between the two separated areas in each region that contribute to the differences in ET, and the assimilation of other observational data may also have some impact on ET.) However, the ET differences between the two separate areas are much larger in ERA-Interim than in MERRA, especially over northern India and the Nile Valley, showing the evident irrigation signals. These differences could be caused by the assimilation of observed temperature and humidity, such that observed cooler temperature or higher humidity over irrigated areas is compensated by added soil moisture in ERA-Interim (Tuinenburg et al. 2012).

\section{c. A simple estimate of irrigation-caused ET increase}

As there is no explicit irrigation over land in MERRA or MERRA-Land, we assume that the irrigation signals in atmospheric forcings have little impact on ET (shown below) and test a simple method to estimate the impact of irrigation on ET. For each land grid point, the total land area includes an irrigated portion $f$ and a nonirrigated portion $1-f$. The total evapotranspiration $\left(E_{\text {total }}\right)$ then comes from both of the land areas:

$$
E_{\text {total }}=E_{\text {irrigated }} f+E_{\text {non-irrigated }}(1-f),
$$

where $f$ can be obtained from the irrigated area dataset, the ET rate over nonirrigated land $\left(E_{\text {non-irrigated }}\right)$ is simply the MERRA-Land output, and the ET rate over irrigated land is estimated as

$$
E_{\text {irrigated }}=(\mathrm{SH}+\mathrm{LH}) \mathrm{EF},
$$

where $\mathrm{SH}+\mathrm{LH}$ is the sum of latent plus sensible heat fluxes and is from MERRA-Land and EF is evaporative fraction (the ratio of $\mathrm{LH}$ to $\mathrm{SH}+\mathrm{LH}$ ). For irrigated land $\mathrm{EF}$ is specified as 0.8 , an estimated value from model simulations (Dirmeyer et al. 2000). Therefore, the ET increase due to irrigation $(d E)$ is

$$
E_{\text {irrigation }}=\max \left[\left(E_{\text {irrigated }}-E_{\text {non-irrigated }}\right) f, 0\right] \text {. }
$$

Evidently,

$$
E_{\text {total }}=E_{\text {non-irrigated }}+E_{\text {irrigation }} .
$$

Figure 3 shows the estimated monthly ET climatology over the four selected irrigation regions for irrigated $\left(E_{\text {total }}\right)$ and nonirrigated $\left(E_{\text {non-irrigated }}\right)$ conditions and their difference $\left(E_{\text {irrigation }}\right)$. The highest estimated irrigation generally happens in the dry and warm season, when the available energy for ET is high but 
MERRA-Land
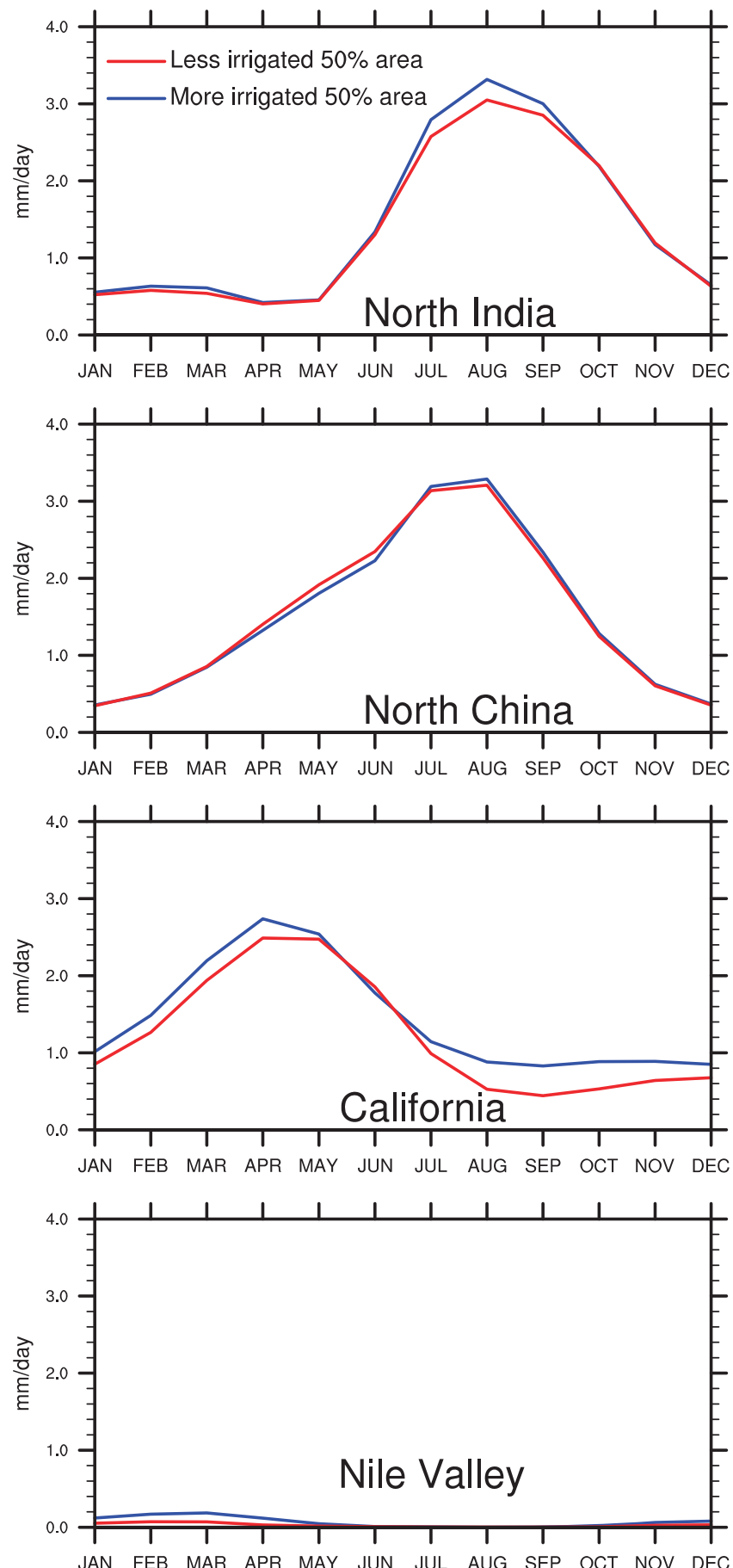

ERA-Interim
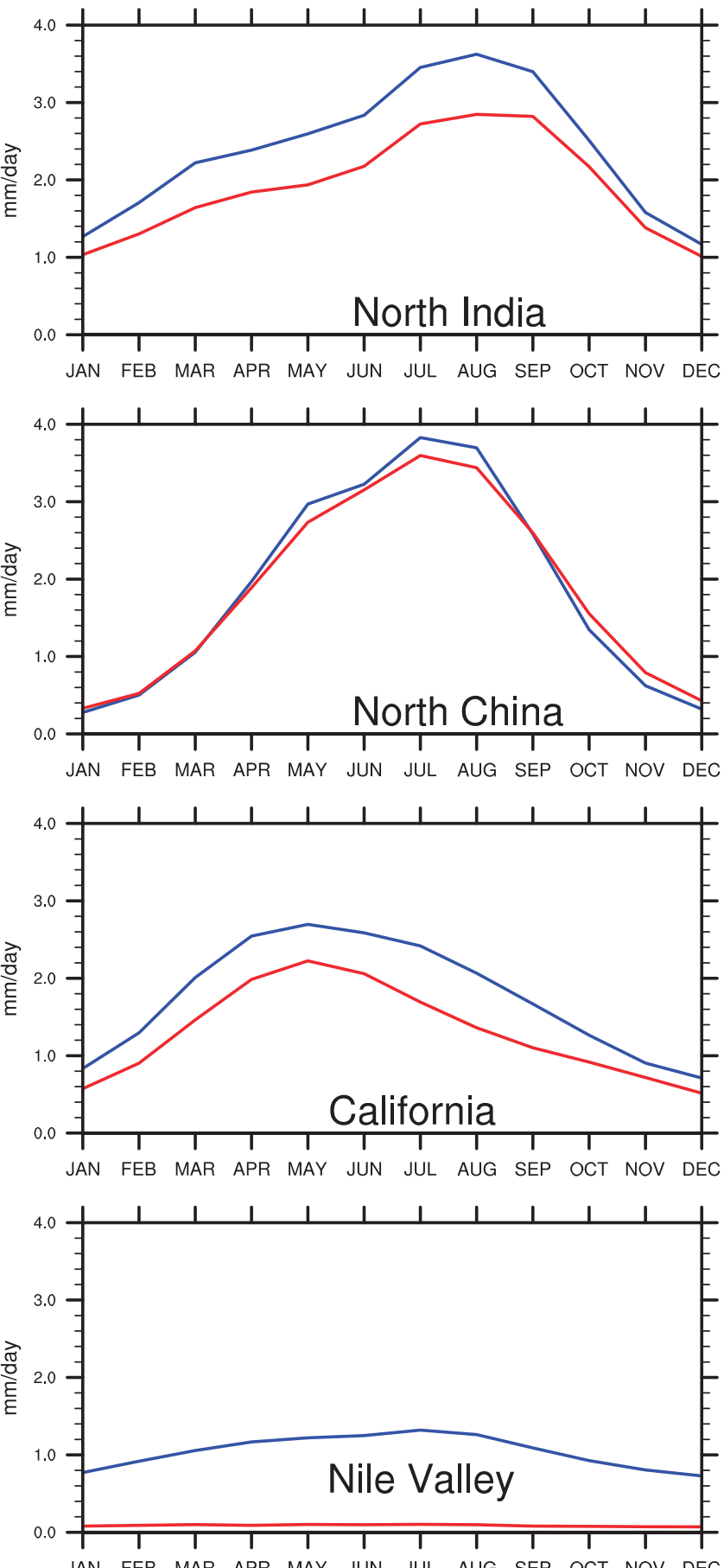

FIG. 2. Monthly ET climatology from (left) MERRA-Land (1979-2008) and (right) ERA-Interim (1979-2010) over two separate halves with high and low irrigation for each region defined in Fig. 1. Ocean grid points and Tibet (altitudes above than $3000 \mathrm{~m}$ ) were removed before separating the areas.

the soil does not contain much water, crudely describing the role of irrigation to provide water for agriculture when demand exceeds the rainfed supply. When the rainy or cold season begins, the irrigation drops.

\section{d. ET from a hydrological model with consideration of human activities}

The method above gives a simple estimate of $d E$ based on energy constraints. However, such a simple 
North India

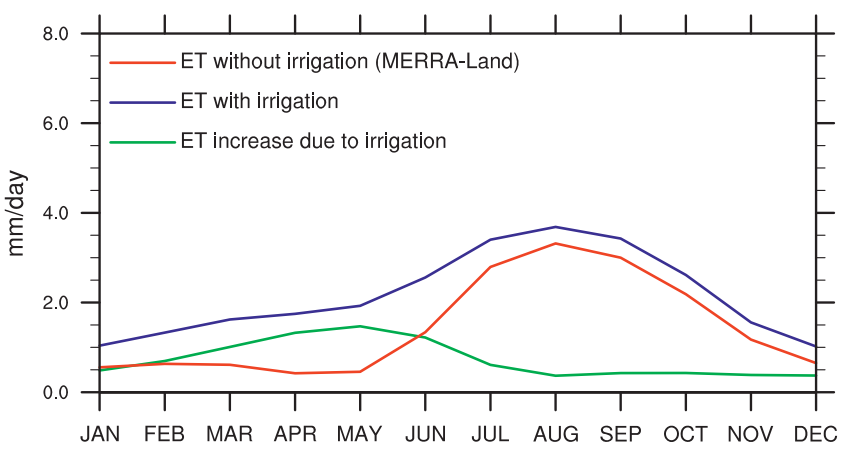

California

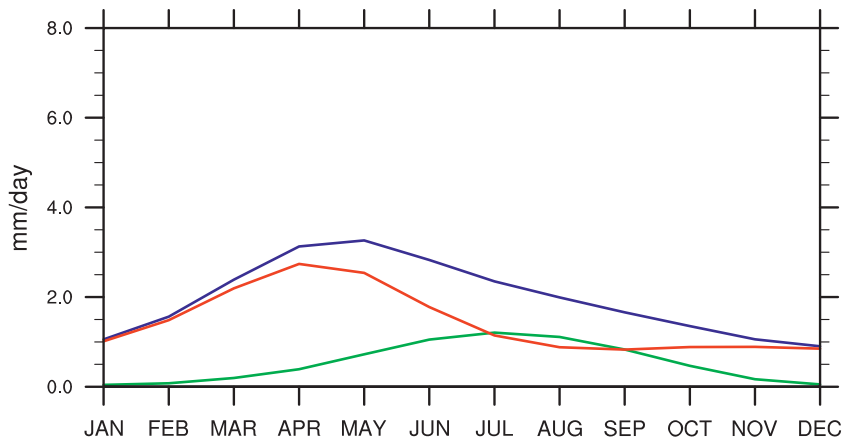

North China

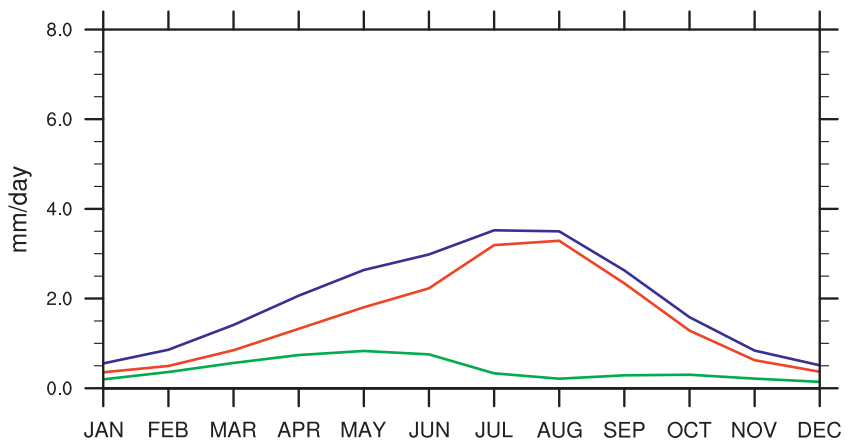

Nile Valley

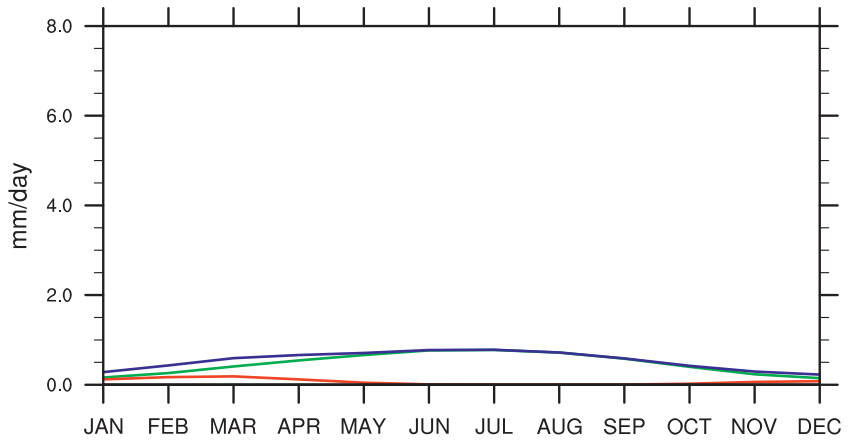

FIG. 3. Estimated monthly ET climatology with and without irrigation and their difference (ET increase due to irrigation) during 19792008 from a simple method and based on MERRA-Land data (see section 2c). The results are only for the more irrigated halves of the four regions (as defined for Fig. 2).

estimate neglects the surface water requirements of different crop types and crop production and also neglects the temporal variations in crop irrigation demand as a result of planting and harvesting. In this study, the ET data from a global reconstruction of hydrography by Wisser et al. (2010) are used to evaluate the simple estimate. The reconstruction uses WBMplus (Vörösmarty et al. 1998), a water balance and transport model that simulates daily irrigation water demand by combining data on irrigation area, growing seasons, cropping patterns, soil properties, and climate. The simulated mean annual irrigation water demand, aggregated by country, correlates well with national statistics reported by the FAO (Wisser et al. 2008). Because of these sophisticated considerations and some proven success, the ET data from the hydrological model are used for further analysis.

Monthly ET data for 1979-2002 from two simulations with the model, a preindustrial run (without irrigation) and a contemporary run (with irrigation), are obtained. Figure 4 shows the reconstructed climatological ET from these two simulations and their difference $d E$. Compared to the simple estimate shown in Fig. 3, the ET without irrigation is similar, but $d E$ is very different, much larger in amplitude, and shifts in seasonality, except over California where the growing season is long. Wisser et al. (2008) found that the irrigation requirement is very sensitive to the factors related to paddy rice. This may be the reason for the high $d E$ over northern India during autumn when the autumn/ winter rice is planted, and this could also be the reason for very high $d E$ over the Nile Valley. The higher $d E$ over northern China during spring and early summer could be caused by the low irrigation efficiency; that is, a large amount of water is lost during conveyance and much of it is transformed to ET (Döll and Siebert 2002).

By comparing Fig. 4 with Fig. 2, we find that the impact of irrigation on ET is very little captured by the reanalyses, especially MERRA, although the atmospheric forcings may contain some irrigation signals from data assimilation. This should be mainly caused by the lack of sophisticated agricultural modeling and land assimilation (e.g., for rice paddy) in the reanalyses, although the estimated irrigation withdrawal from this hydrological model is a little higher than that from other studies (Guimberteau et al. 2012). We can therefore assume that the ET from MERRA-Land contains no irrigation, and the irrigation-caused ET increase can be added to it to represent the effect of irrigation. 
North India

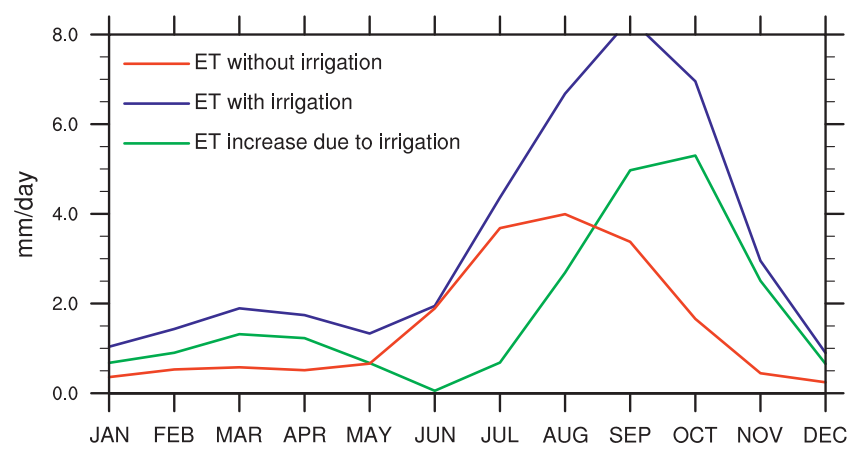

California

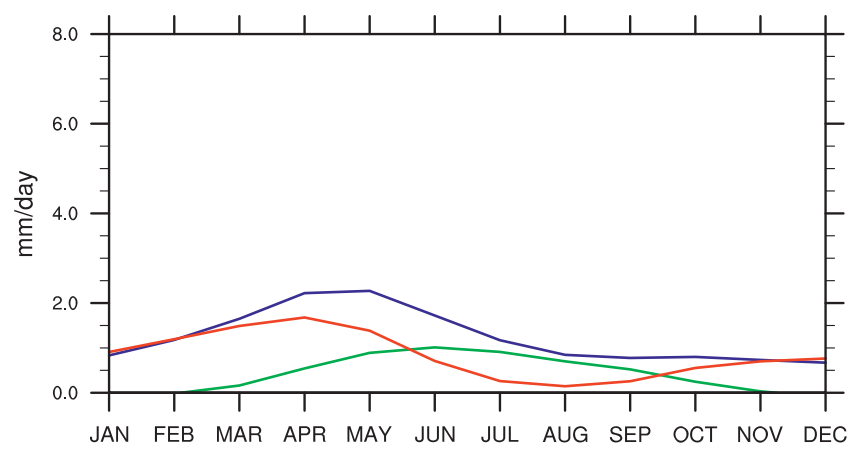

North China

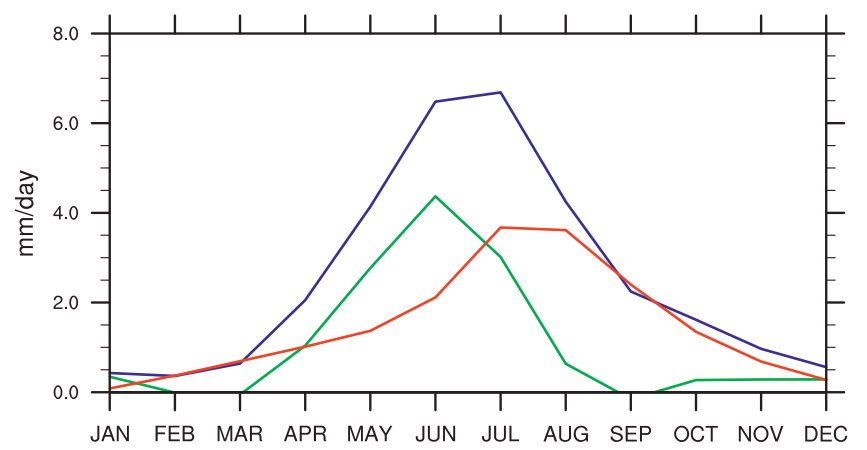

Nile Valley

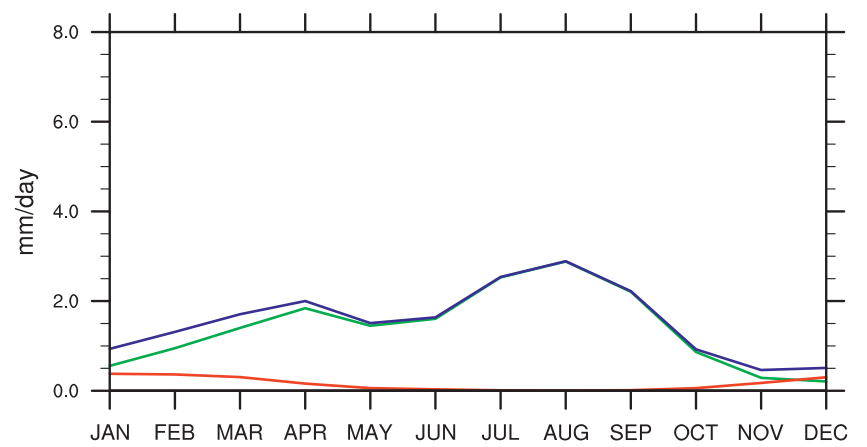

FIG. 4. As in Fig. 3, but from the preindustrial (ET without irrigation) and contemporary (ET with irrigation) simulations of Wisser et al. (2010) for 1979-2002.

\section{e. Quasi-isentropic back-trajectory method and data used}

The quasi-isentropic back-trajectory (QIBT) method (Dirmeyer and Brubaker 1999, 2007; Brubaker et al. 2001) is used to track the water vapor for each precipitation event backward in time along the isentropic surfaces, assuming precipitated water is drawn from the atmospheric column in a distribution that follows the vertical profile of specific humidity. Traces start from the grid box that has precipitation and from the time step when precipitation occurs, backward in space and time until all of its original precipitation is attributed to ET, but no longer than 15 days (the average residence time of moisture in the atmosphere is about 10 days). The time step for calculation is $45 \mathrm{~min}$, and the calculations and output are aggregated into pentads. See the reference papers above for a detailed description of the QIBT method. An advantage of the QIBT method compared to using water vapor tracers in models (e.g., Druyan and Koster 1989; Numaguti 1999; Bosilovich and Schubert 2002) is that it can be applied a posteriori to 3D analysis data, and the study region can be defined after the model simulation has been finished. Several similar methods have been developed to examine the water vapor sources for precipitation (e.g., Stohl and James 2004; Sodemann et al. 2008; van der Ent et al. 2010).

The required data for the QIBT calculation include precipitation and ET at the surface and temperature, humidity, and wind at different tropospheric levels, preferably at a subdiurnal time step (6-hourly data are used in this study). All data are from the original MERRA except ET and precipitation. Since we are concerned with the impact of irrigation, monthly $d E$ from the hydrological model (section 2d) is added to the daily ET data from MERRA-Land by scaling, and this new ET data are used to correct the 6-hourly MERRA ET. Daily gauge-based Climate Prediction Center (CPC) unified precipitation (Xie et al. 2007; Chen et al. 2008) is used to correct the MERRA precipitation. It has a spatial resolution of $0.5^{\circ} \times 0.5^{\circ}$ and covers global land. The two corrections are made at the pentad time scale by multiplying the original MERRA variable at each time step with a ratio of the pentad-average value of the target (MERRALand ET plus irrigation or CPC unified precipitation) and the pentad-average value from original MERRA. Note that small negative ET changes also happen over some areas. They are considered in the QIBT run, but ET from these areas is not counted as a contribution from irrigation. 
a) Annual ET increase (mm)

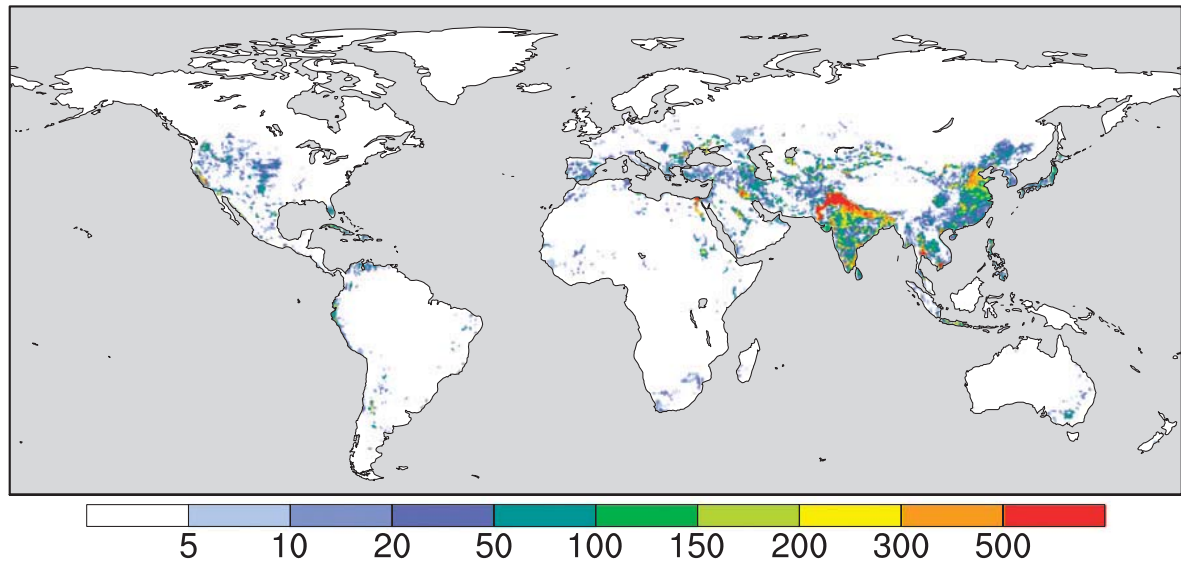

b)

Percentage of ET increase (\%)

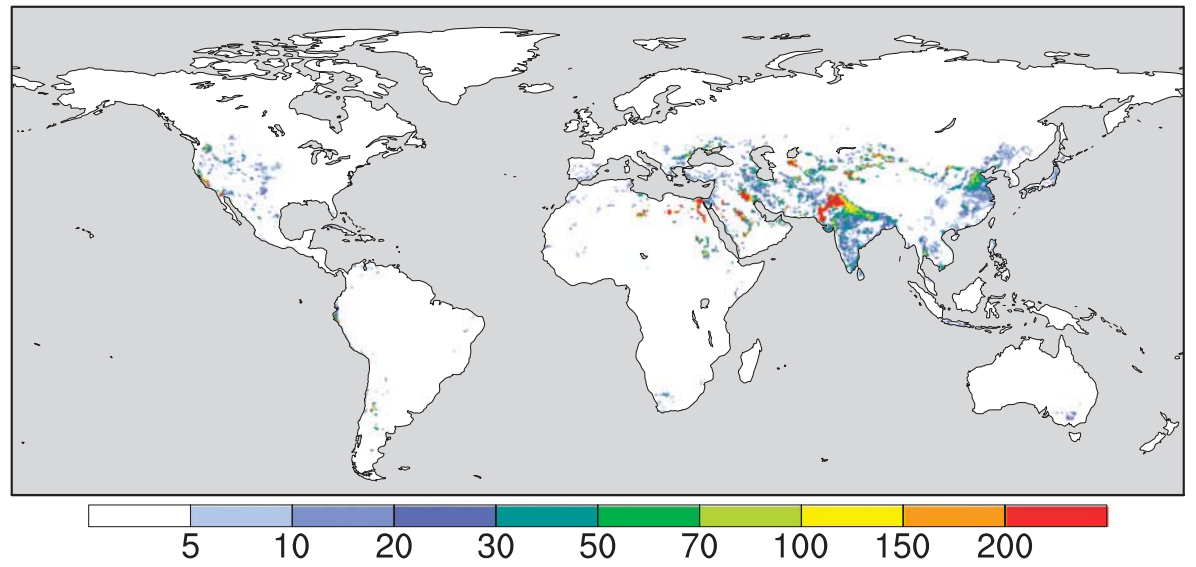

FIG. 5. (a) Ten-year (1986-95) mean annual total ET increases due to irrigation (the difference between the contemporary and preindustrial simulations of Wisser et al. 2010). (b) The percentage of ET increases relative to the mean preindustrial condition. Almost identical results are found for the 24-yr (1979-2002) average.

The QIBT run is performed for the 10-yr period 198695. Calculations are only made for the northern low- and midlatitude $\left(5^{\circ}-55^{\circ} \mathrm{N}\right)$ land where most irrigated areas are located. The output is a spatial distribution of the evaporative sources for precipitation over each grid point (cf. Dirmeyer and Brubaker 1999, 2007; Dirmeyer and Kinter 2010; Wei et al. 2012). We can calculate the impact of $d E$ over a certain region on precipitation over local and surrounding regions by aggregating the evaporative contribution from this region. In estimating the impact of $d E$, we assume $d E$ accounts for a fixed portion of the total ET over each grid point during a month.

\section{Results}

Figure 5 shows the mean annual $d E$, which is the difference between the contemporary run and preindustrial run of the hydrological model, as introduced in section $2 \mathrm{~d}$. For the convenience of comparison, data for the same 10-yr period as the QIBT run is shown. The spatial pattern of $d E$ is very similar to the percentage of land dedicated to irrigation shown in Fig. 1. Figure 5b demonstrates that after irrigation is considered ET is almost doubled over northern China and northern India and more than tripled over northwestern India and Pakistan, the Nile Valley, and some small areas over the Middle East, California, etc. This illustrates the importance of human activities on surface ET over some regions, although the global average $d E$ over land (shown in Fig. 5) is only about $2.5 \%$.

Figure 6 shows the amount of precipitation coming from irrigation $(d P)$ and its fraction in total precipitation $(d P / P)$ estimated from the 10-yr QIBT analysis. The $d P$ is high over India and northern Pakistan, central and northern China, and northwestern Ethiopia, basically consistent with the pattern of ET increase but also 
a) Annual precip. from irrigation $(\mathrm{mm})$

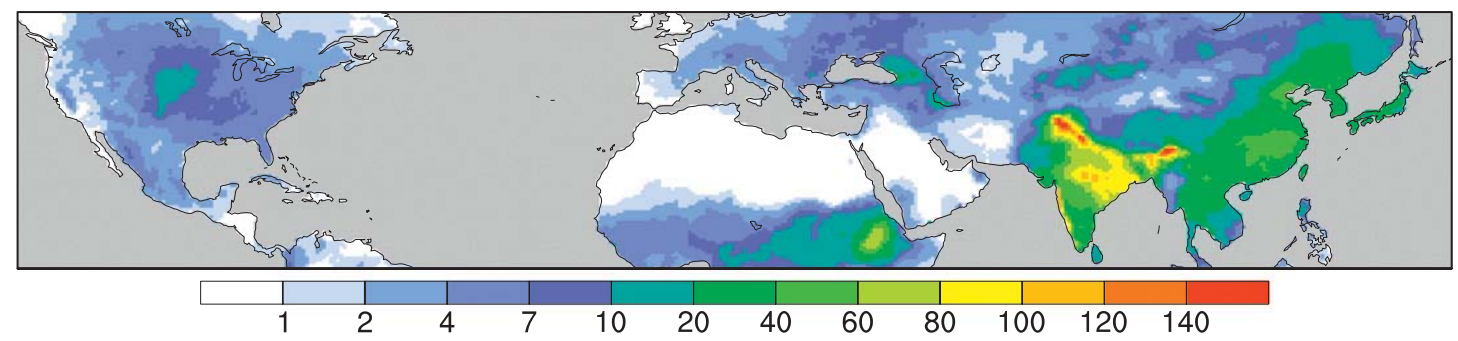

b)

Percentage of total precip. (\%)

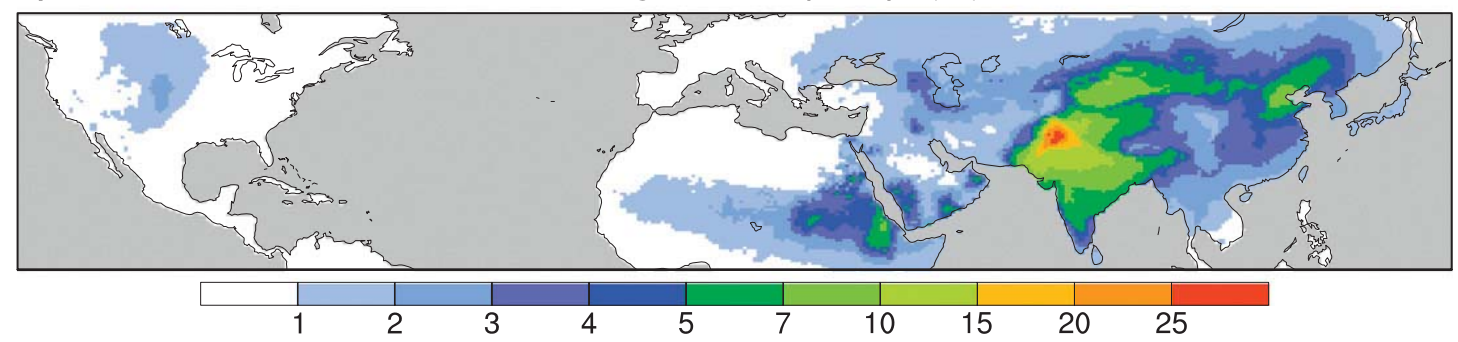

FIG. 6. Results of the 10-yr QIBT analysis that shows (a) the mean annual total precipitation from irrigation and (b) the percentage of the total precipitation that is from irrigation.

representing the nonlocal moisture transfers. The fraction of total precipitation that is $d P$ shows a different pattern, with high values over northwestern India and Pakistan, western China, and northern China. On average, only $1.8 \%$ of the land precipitation $\left(5^{\circ}-55^{\circ} \mathrm{N}\right)$ is from irrigation. The average $d E$ over northern land $\left(5^{\circ}-55^{\circ} \mathrm{N}\right)$ is $22.71 \mathrm{~mm} \mathrm{yr}^{-1}$ (shown in Fig. 5a), but $d P$ over the same area is $10 \mathrm{~mm} \mathrm{yr}^{-1}$. As the long-term moisture change in the atmosphere is negligible, the remainder of $d E$ should mostly contribute to the precipitation over ocean.

In addition to $d E$, the patterns in Fig. 6 are related to other factors such as the wind field and climate over local and surrounding regions. The strength and pattern of the wind field determines whether the impact is local or more remote, and the regional climate conditions control the impact of ET increase on precipitation (Findell et al. 2011; Wei and Dirmeyer 2012). To examine these impacts, we investigate the relationship between $d P$ and $d E$. Figure 7a shows the ratio of $d P / d E$ during March-November; the boreal winter months are excluded owing to the weak impact of ET on precipitation. The data are interpolated to $5^{\circ} \times 5^{\circ}$ grids to highlight regional budgets. The irrigation regions with $d P / d E$ less than 1 (precipitation increase is less than the water loss) may experience water deficits if there are not enough renewable water resources (e.g., rivers), while regions with $d P / d E>1$ are less likely to have water deficits. It can be seen that $d P / d E$ is less than 1 over most irrigated areas, consistent with the results above. The heavily irrigated regions usually have a small value of $d P / d E ; d P / d E$ is greater than 1 over a few regions, including southeast India, southwest China, northeast China, and the Korean peninsula. They are usually downwind of the regions with high $d E$ but have small $d E$ themselves, indicating that they are not heavily irrigated. According to Wada et al. (2010), these regions are a few that are not under large groundwater depletion, supporting our results.

Separating the irrigated grids in Fig. 7a into dry and wet halves, Fig. $7 \mathrm{~b}$ shows that $d P$ increases with $d E$, and for the same $d E$ wet areas have significantly larger $d P$ than dry areas. Figure $7 \mathrm{c}$ further shows that the percentage precipitation increases $(d P / P)$ are actually very similar over dry and wet areas, and they both increase with $d E$. This means that the relative contribution of $d E$ to precipitation is similar over all regions and higher $d E$ leads to higher $d P / P$. Evapotranspiration increases over dry regions struggle to produce enough CAPE to trigger local precipitation, and the moisture is instead advected away. In humid regions the ET increase can more easily enhance convective instability and contribute to increased precipitation (e.g., Dirmeyer et al. 2010). Our results are supported by those from some numerical experiments. For example, Segal et al. (1998) found that the precipitation increase in response to irrigation typically occurs over areas with existing precipitation, and Ter Maat et al. (2006) showed that the large-scale irrigation over southwest Saudi Arabia can lead to very limited water recycling and rainfall generation. Note that we emphasize the impact of ET increase on precipitation in the perspective of water 
a) $\mathrm{dP} / \mathrm{dE}$

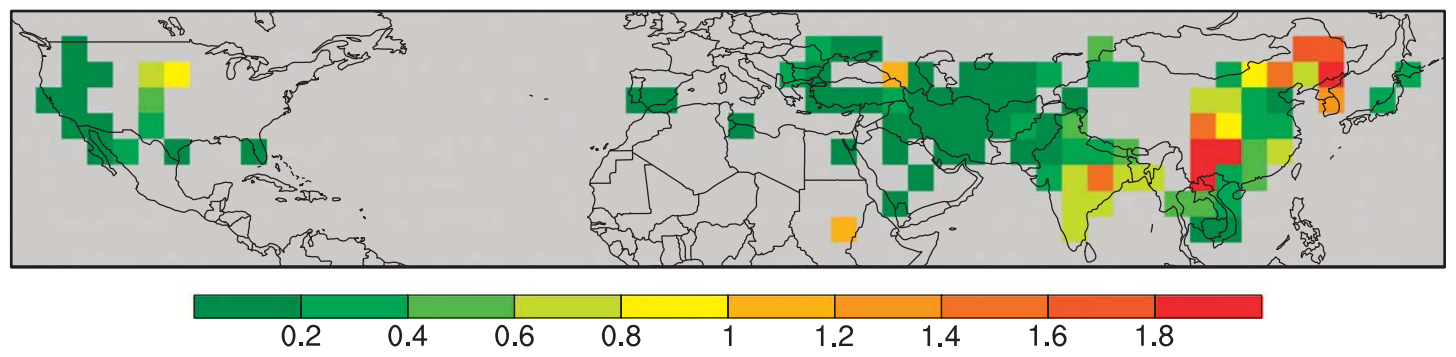

b)

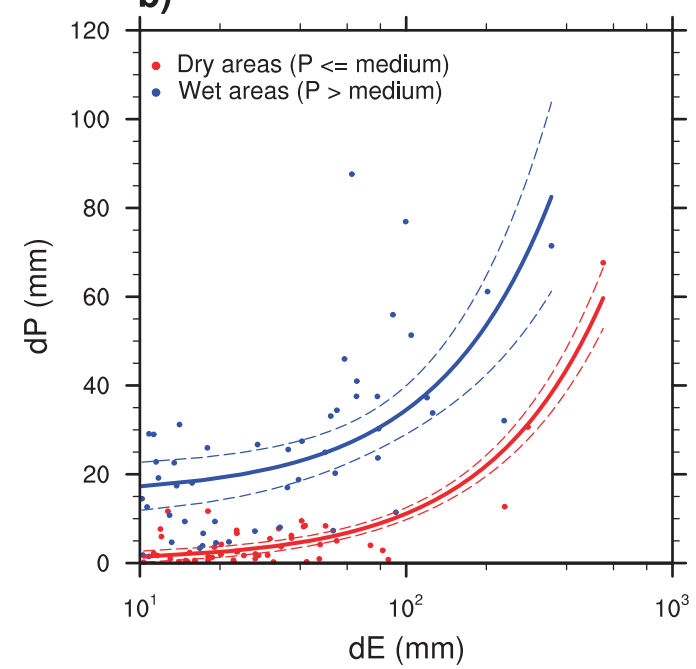

c)

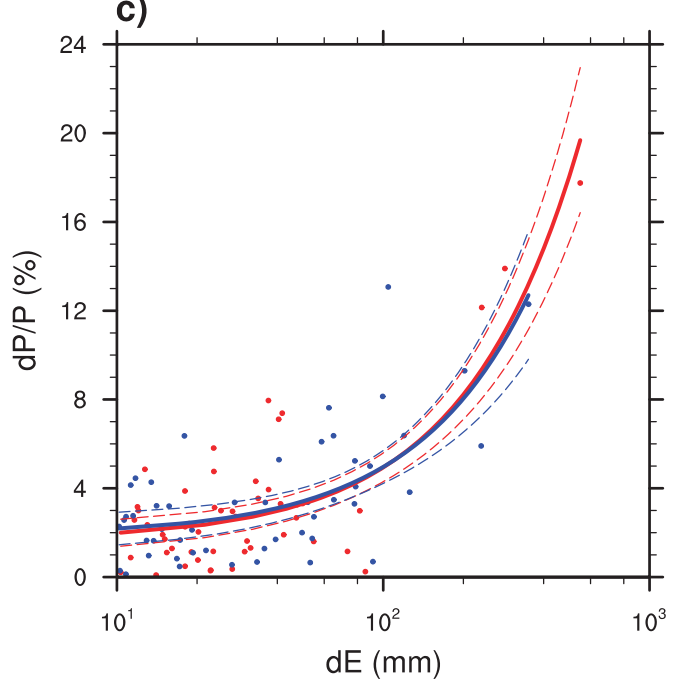

FIG. 7. (a) Ratio of March-November total precipitation increase $(d P)$ and ET increase $(d E)$ due to irrigation over $5^{\circ} \times 5^{\circ}$ grid boxes. Only grid boxes with $d E>10 \mathrm{~mm}$ are shown. (b) Scatterplot of $d P$ and $d E$ for each grid box in (a). (c) Scatterplot of $d P / P$ and $d E$ for each grid box in (a). The grid boxes are separated into two equal-sized groups (red and blue colors) according to their total precipitation, and their respective linear regressions are shown (they are not straight in the figure because of the log scale). The dashed lines are their respective $95 \%$ confidence intervals. The regressions are significant at $p<0.01$ level even when using a conservative estimate of the degree of freedom of onethird of the sample size due to spatial correlations.

cycle, that is, by contribution of water vapor, which is somewhat different from the impact of ET on the variation and prediction of precipitation (Wei and Dirmeyer 2012).

Next, the contributions of irrigation to precipitation are calculated and discussed separately for each of the four heavily irrigated regions. Figure 8 shows the contribution of irrigation over northern India to regional precipitation. This region is the most heavily irrigated region in the world as measured by both the percentage of land equipped for irrigation (Fig. 1) and $d E$ (Fig. 5). Satellite-based observations have shown strong depletion of groundwater over this region in recent years (Rodell et al. 2009). Figure 8 shows that, although irrigation has a strong impact on local precipitation, it also affects precipitation outside of the irrigation region, especially downwind (Figs. 8a,b). The biggest impact on $d P$ is during August-September (Figs. 8c,d), although $d E$ is largest during September-October (Fig. 4). This is because August is much more humid than October and, according to the mechanism discussed above, it is much easier for enhanced precipitation to be triggered. The $d P / P$ is highest during October (Figs. 8e,f) with a local (inner box) average of $15.2 \%$ and high values above $60 \%$ over northwest India and eastern Pakistan (not shown), but the actual precipitation is low during this time (less than $5 \mathrm{~mm}$ month $^{-1}$ ).

The north China plain is one of the main agricultural regions in China and has a very dense population. Irrigation over this region also affects local and remote precipitation but is smaller in amplitude than over northern India (Fig. 9). This is related to both the irrigated area and irrigation amount, which are both smaller. A large amount of the irrigation over this region is transported to the northeast by the monsoon flow during June-July when irrigation and its impacts are largest. The $d P / P$ is highest during June with a local average of $6.3 \%$ and high values above $12 \%$ over southeast Beijing, northwest Tianjin, and part of Hebei province. 
a) Annual precip. from irrigation $(\mathrm{mm})$

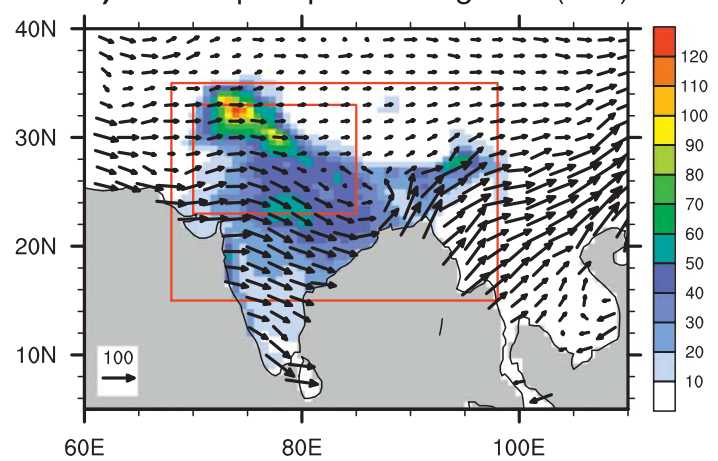

c) Zonal average $(\mathrm{mm} / \mathrm{mon})$



b) Percentage of total precip. (\%)

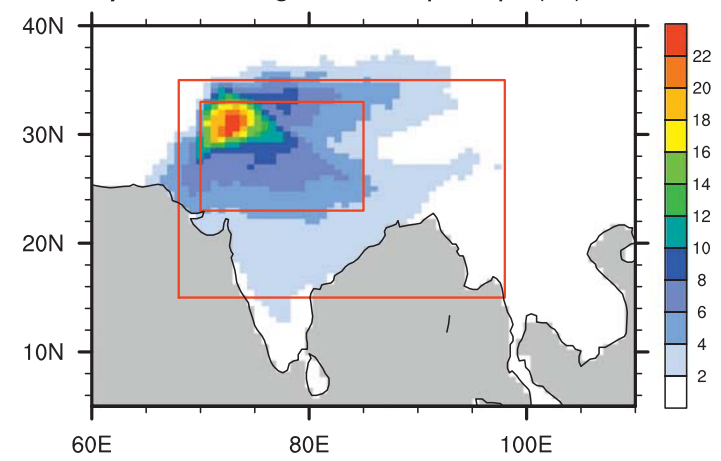

d) Meridional average $(\mathrm{mm} / \mathrm{mon})$
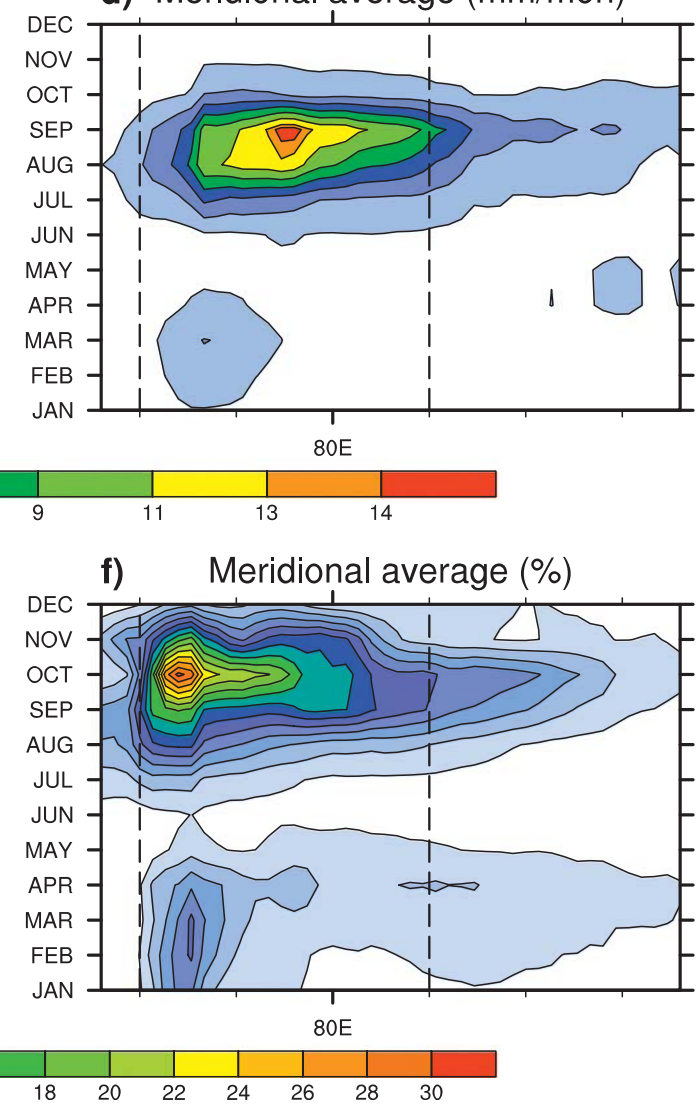

FIG. 8. (a) The results from 10-yr QIBT analysis showing the mean annual total precipitation ( $\mathrm{mm}$ ) from northern India irrigation in the inner red box (shaded). The outer red box is the area for zonal or meridional averages in (c)-(f). The arrows show the annual average vertically integrated moisture flux $\left(\mathrm{kg} \mathrm{m}^{-1} \mathrm{~s}^{-1}\right)$. (b) Percentage of the total precipitation that is from irrigation in the inner red box. (c) Latitude-time plot for the monthly climatology of zonal average contribution of irrigation to precipitation $\left(\mathrm{mm} \mathrm{month}^{-1}\right)$. The horizontal dashed lines are the north and south boundaries of the source region [inner red box in (a)]. (d) As in (c), but the longitude-time plot for the meridional averages. The vertical dashed lines are the west and east boundaries of the source region. (e) As in (c), but shown as the percentage of total precipitation. (f) As in (e), but the longitude-time plot.

The California Central Valley is a major agricultural region in the United States. Irrigation water, mainly from snowmelt and groundwater, is very important for agriculture in this region. Figure 10 shows the contribution of irrigation over this region to precipitation. It can be seen that the contributions are much weaker than for northern India or northern China, which is related to the smaller irrigated area and the dry climate over surrounding regions. The location that is most affected in amount moves from local areas in May to remote locations (Montana, Wyoming, South Dakota, and North Dakota) by July. The local $d P / P$ is highest 
a) Annual precip. from irrigation $(\mathrm{mm})$

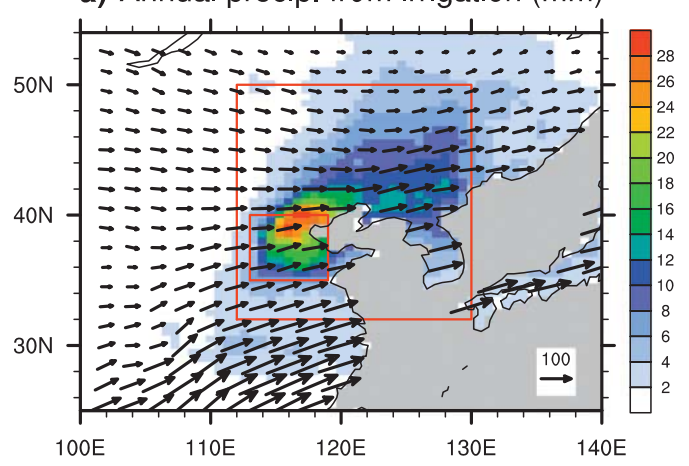

c) Zonal average $(\mathrm{mm} / \mathrm{mon})$

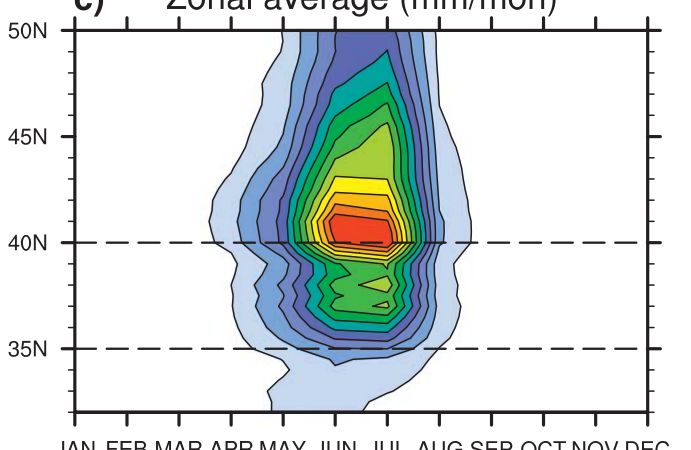

b) Percentage of total precip. (\%)

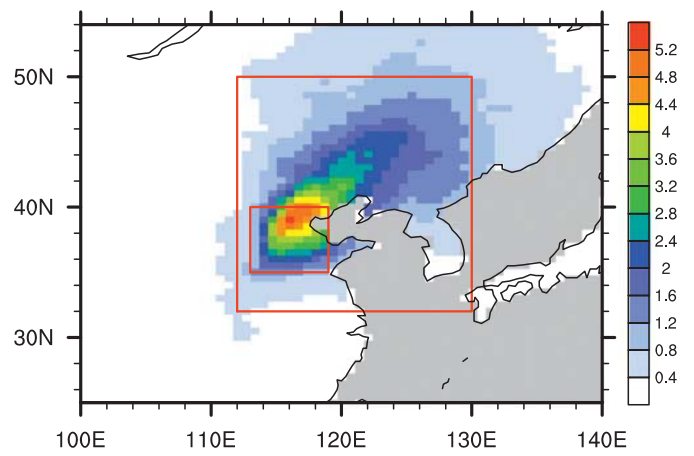

d) Meridional average $(\mathrm{mm} / \mathrm{mon})$

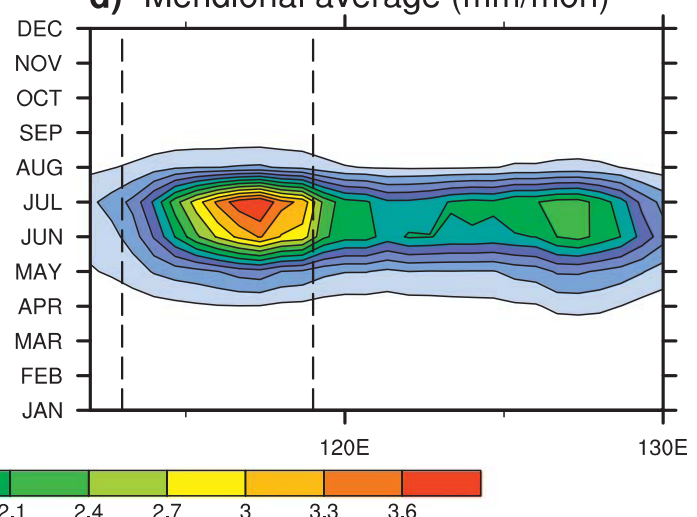

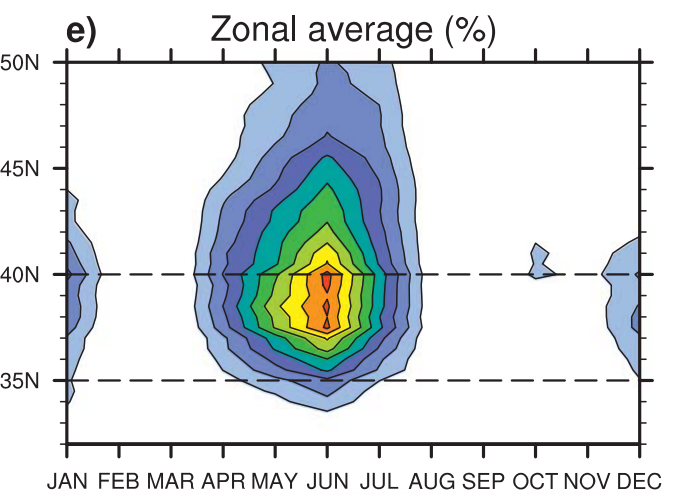

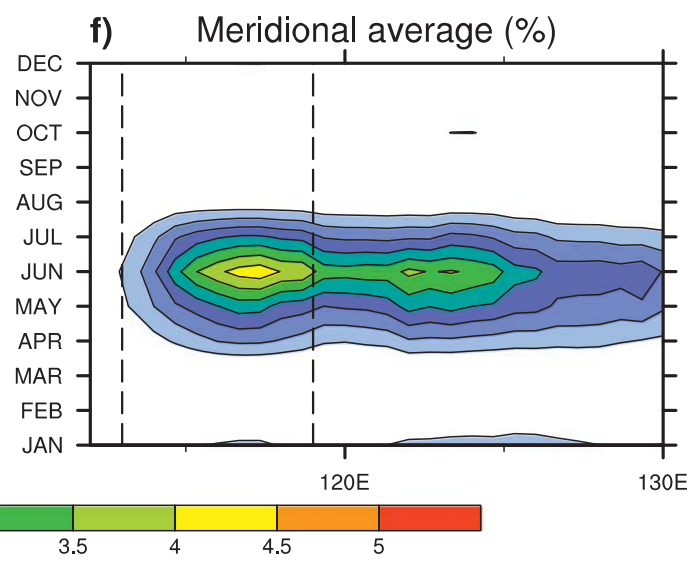

FIG. 9. As in Fig. 8, but for irrigation over northern China.

during July with an area average of $1.9 \%$ and peak values over $10 \%$.

The Nile Valley is a unique agricultural region that lies within a severe desert. It mainly depends on water from the Nile River for irrigation. Because of the very dry climate over this region, the evaporated irrigation water is transported far afield, south to Ethiopia and southern Sudan and northeast to western Asia, where the climates are more humid (Fig. 11). The most affected region is Ethiopia during July-August, but it only accounts for a very small percentage of the total precipitation there. The percentage contribution is still highest locally, where on average $3 \%$ of the total precipitation is from irrigation water during August.

\section{Summary and discussion}

It is well known that irrigation can greatly alter the land surface energy and water fluxes, but the contribution of irrigation water to precipitation is less well understood because of limits in modeling and observations. By comparing the evapotranspiration (ET) estimates with and without irrigation from the reanalyses themselves and from a hydrological model with detailed 
a) Annual precip. from irrigation (mm)
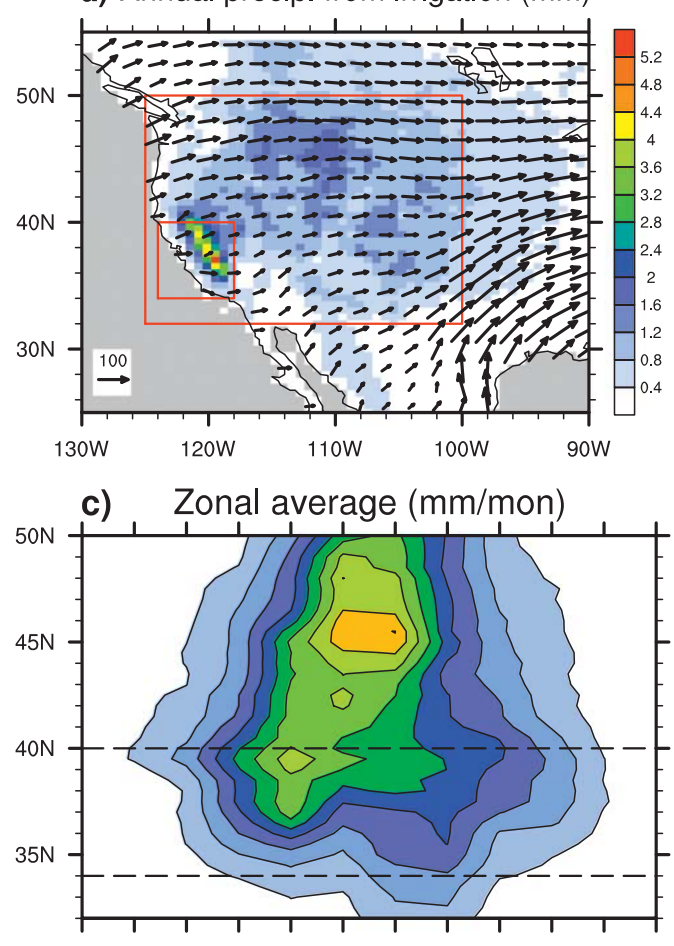

b) Percentage of total precip. (\%)

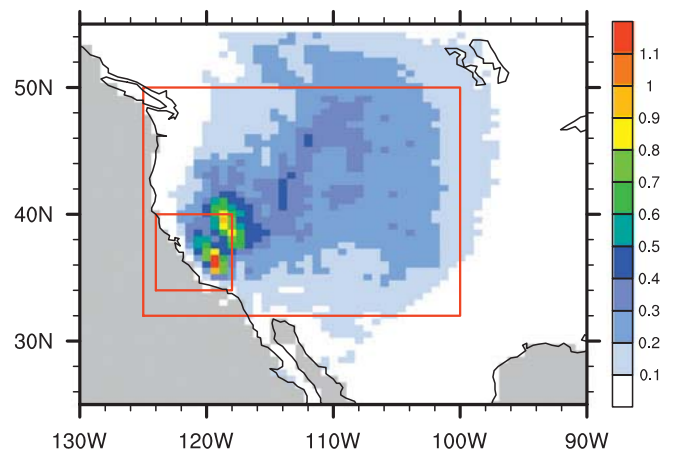

d) Meridional average $(\mathrm{mm} / \mathrm{mon})$

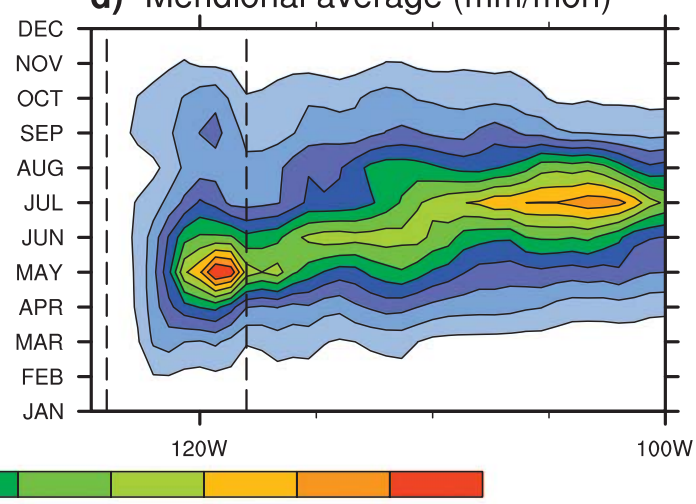

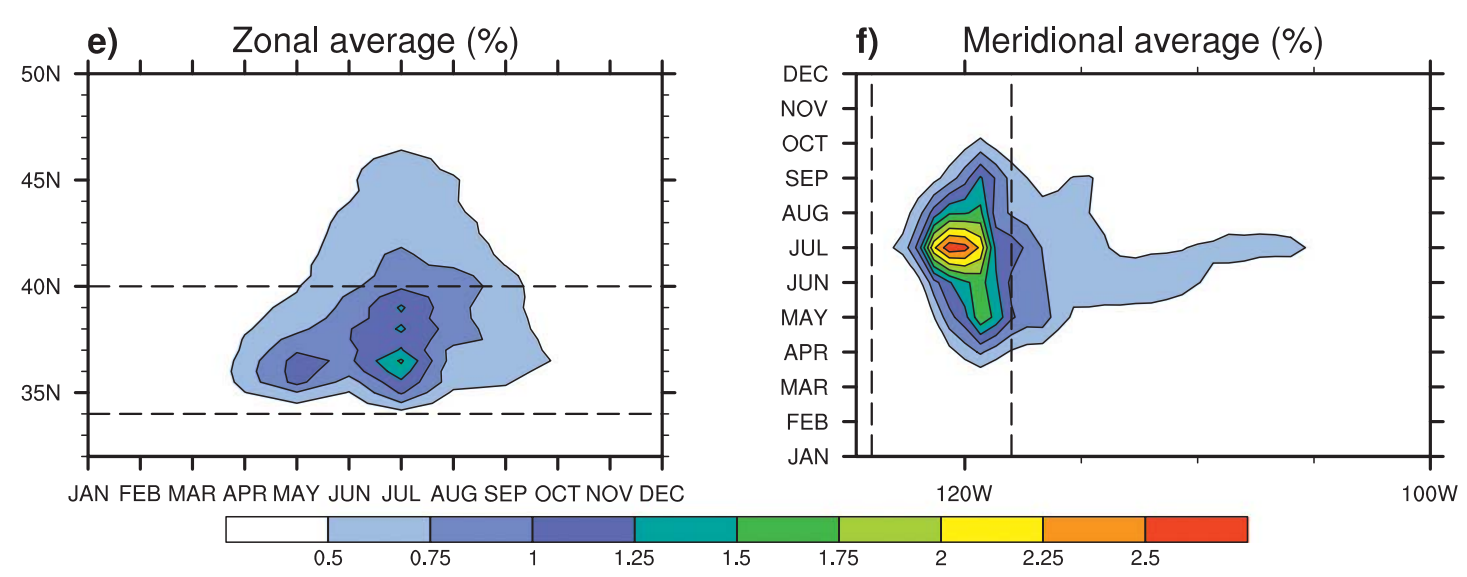

FIG. 10. As in Fig. 8, but for irrigation over California.

considerations of agriculture, this study first demonstrates the deficiency of ET estimates from MERRALand by showing that it has little consideration of the impact of irrigation, which can be very large over some regions. This enables us to add additional ET from irrigation to the ET of MERRA-Land and separate the impact of irrigation on precipitation. The quasi-isentropic back-trajectory (QIBT) method is used to determine the evaporative moisture sources for precipitation over land using MERRA, but the ET of MERRA is corrected using ET from MERRA-Land plus estimated ET increase due to irrigation, and
MERRA precipitation is corrected using CPC unified precipitation.

Results show that the irrigation-caused precipitation increase is locally large over some heavily irrigated regions, like northern India, eastern Pakistan, and central and northern China, but it is very small in amount and percentage for the global average. Irrigation-caused precipitation increase is less than the ET increase over most areas, indicating that irrigation may be unsustainable over these regions if there are not enough sustainable water resources. For the same ET increase, precipitation increases are greater over wet areas than 
a) Annual precip. from irrigation ( $\mathrm{mm}$ )

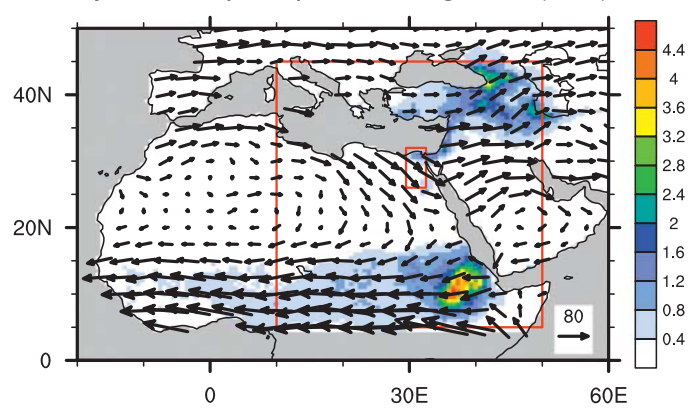

c) Zonal average $(\mathrm{mm} / \mathrm{mon})$



e)

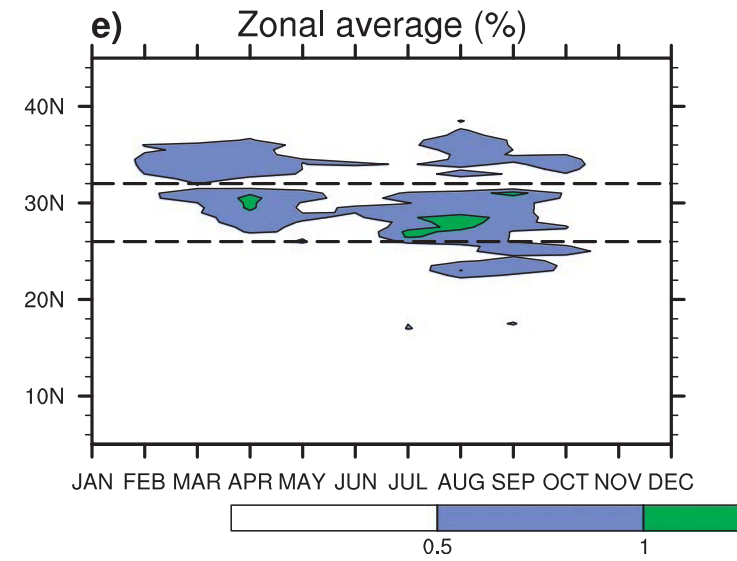

b) Percentage of total precip. (\%)

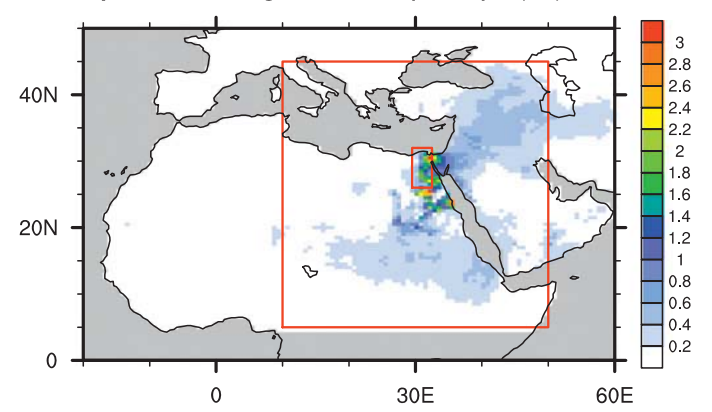

d) Meridional average ( $\mathrm{mm} / \mathrm{mon}$ )
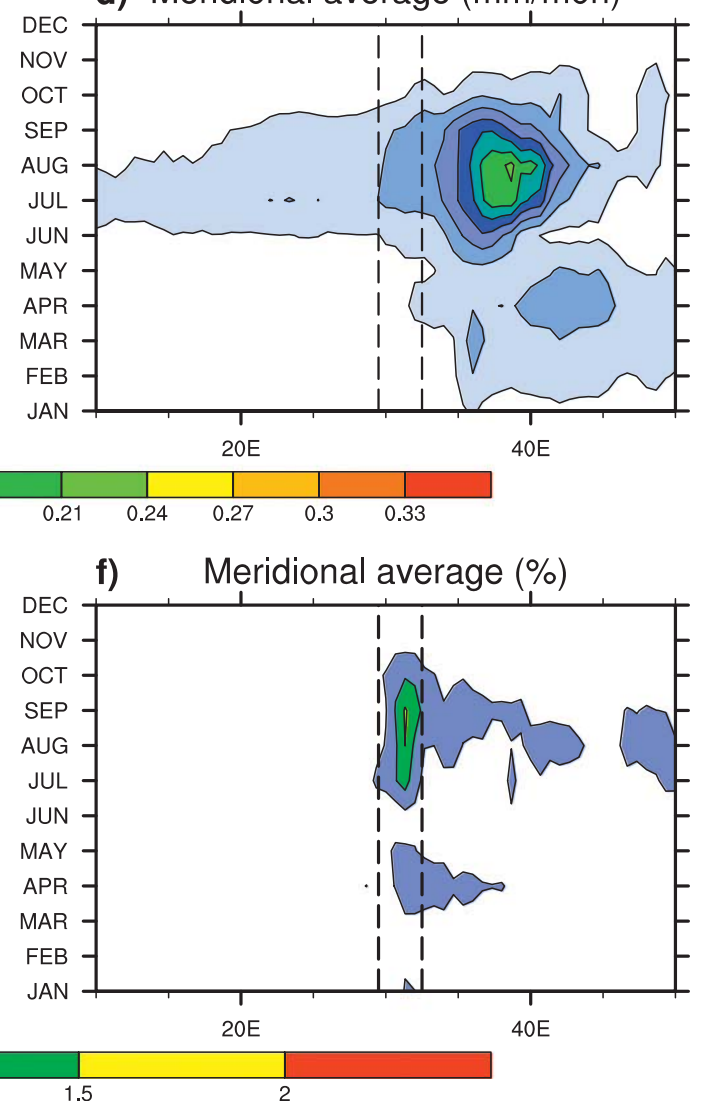

FIG. 11. As in Fig. 8, but for irrigation over the Nile Valley.

dry areas, but the percentage increases in precipitation are similar and are proportional to the ET increase. Water vapor from irrigation-caused ET increases over arid regions is mostly transported to more humid regions where a small increase in humidity can trigger increased precipitation. Four heavily irrigated regions are selected for detailed analysis. Although they show differences in contribution to local and remote precipitation, which are related to wind and regional climate, all of them show the highest percentage contribution to precipitation over local land areas.

As discussed, the ET from MERRA-Land may already contain some small contribution from irrigation because of the atmospheric data assimilation. This may lead to overestimation of the ET without irrigation and underestimation of the fraction of ET from irrigation. However, the total ET with irrigation is also overestimated. Therefore, the total impact of the bias on the estimated irrigation-caused precipitation is uncertain. Although there are uncertainties in the method and irrigation data and biases in MERRA, this study for the first time systematically estimates the direct contribution of irrigation water to precipitation from a water cycle perspective. The estimates in this study are calculated under the same atmospheric circulation and, so, are complementary to the previous estimates from 
model simulations and observations, which are not suited to separate direct effect from secondary impacts and feedbacks.

This study shows that simple estimates of irrigation based on energy limits or soil moisture, which have been used by some previous studies, often underestimate or introduce seasonal biases in the irrigation impacts on ET. This has also been shown by Guimberteau et al. (2012; cf. their Fig. 9). If such simple estimates are used in climate simulations, the irrigation-caused climate effects could be underestimated or incorrectly estimated. Our study shows that irrigation can more than double ET without irrigation over some regions, which could lead to significant climate effects in addition to precipitation changes. Some studies show that the regional effect of irrigation could be as large as those seen for land cover change (e.g., Sacks et al. 2009; Douglas et al. 2009). This suggests that irrigation and its related water management should be seriously considered in future projections of climate change.

Acknowledgments. This research was supported by National Aeronautics and Space Administration Grant NNX09AI84G. We thank Qing Liu and Rolf Reichle for providing an early version of the MERRA-Land data set and Min-Hui Lo for earlier discussion.

\section{REFERENCES}

Adegoke, J. O., and Coauthors, 2003: Impact of irrigation on midsummer surface fluxes and temperature under dry synoptic conditions: A regional atmospheric model study of the U.S. high plains. Mon. Wea. Rev., 131, 556-564.

Betts, A. K., J. H. Ball, A. C. M. Beljaars, M. J. Miller, and P. A. Viterbo, 1996: The land surface-atmosphere interaction: A review based on observational and global modeling perspectives. J. Geophys. Res., 101, 7209-7225.

Bosilovich, M. G., and S. D. Schubert, 2002: Water vapor tracers as diagnostics of the regional hydrologic cycle. J. Hydrometeor., 3, 149-165.

Boucher, O., G. Myhre, and A. Myhre, 2004: Direct human influence of irrigation on atmospheric water vapour and climate. Climate Dyn., 22, 597-603, doi:10.1007/s00382-004-0402-4.

Brubaker, K. L., P. A. Dirmeyer, A. Sudradjat, B. Levy, and F. Bernal, 2001: A 36-yr climatological description of the evaporative sources of warm-season precipitation in the Mississippi River basin. J. Hydrometeor., 2, 537-557.

Chase, T. N., R. A. Pielke Sr., T. G. F. Kittel, J. S. Baron, and T. J. Stohlgren, 1999: Potential impacts on Colorado Rocky Mountain weather due to land use changes on the adjacent Great Plains. J. Geophys. Res., 104, 16 673-16 690.

Chen, M., W. Shi, P. Xie, V. B. S. Silva, V. E. Kousky, R. W. Higgins, and J. E. Janowiak, 2008: Assessing objective techniques for gauge-based analyses of global daily precipitation. J. Geophys. Res., 113, D04110, doi:10.1029/2007JD009132.

DeAngelis, A., F. Dominguez, Y. Fan, A. Robock, M. D. Kustu, and D. Robinson, 2010: Evidence of enhanced precipitation due to irrigation over the Great Plains of the United States. J. Geophys. Res., 115, D15115, doi:10.1029/2010JD013892.

Dee, D. P., and Coauthors, 2011: The ERA-Interim reanalysis: Configuration and performance of the data assimilation system. Quart. J. Roy. Meteor. Soc., 137, 553-597.

Dirmeyer, P. A., and K. L. Brubaker, 1999: Contrasting evaporative moisture sources during the drought of 1988 and the flood of 1993. J. Geophys. Res., 104, 19 383-19 397.

— , and — 2007: Characterization of the global hydrologic cycle from a back-trajectory analysis of atmospheric water vapor. J. Hydrometeor., 8, 20-37.

— gional water cycle perspective. J. Hydrometeor., 11, 1172-1181.

—_, and Coauthors, 2000: The sensitivity of surface fluxes to soil water content in three land surface schemes. J. Hydrometeor., 1, 121-134.

—- X. Gao, M. Zhao, Z. Guo, T. Oki, and N. Hanasaki, 2006: GSWP-2: Multimodel analysis and implications for our perception of the land surface. Bull. Amer. Meteor. Soc., 87, 1381-1397.

— Z Z. Guo, and J. Wei, 2010: Building the case for (or against) land-driven climate predictability. iLEAPS Newsletter, No. 9, University of Helsinki, Helsinki, Finland, 14-17.

Döll, P., and S. Siebert, 2002: Global modeling of irrigation water requirements. Water Resour. Res., 38, 1037, doi:10.1029/ 2001WR000355.

Douglas, E. M., A. Beltrán-Przekurat, D. Niyogi, R. A. Pielke Sr., and C. J. Vörösmarty, 2009: The impact of agricultural intensification and irrigation on land-atmosphere interactions and Indian monsoon precipitation-A mesoscale modeling perspective. Global Planet. Change, 67, 117-128, doi:10.1016/ j.gloplacha.2008.12.007.

Douville, H., P. Viterbo, J.-F. Mahfouf, and A. C. M. Beljaars, 2000: Evaluation of the optimum interpolation and nudging techniques for soil moisture analysis using FIFE data. Mon. Wea. Rev., 128, 1733-1756.

Druyan, L. M., and R. D. Koster, 1989: Sources of Sahel precipitation for simulated drought and rainy seasons. J. Climate, 2, 1438-1446.

Findell, K. L., and E. A. B. Eltahir, 2003: Atmospheric controls on soil moisture-boundary layer interactions. Part II: Feedbacks within the continental United States. J. Hydrometeor., 4, 570-583.

— in eastern United States and Mexico enhanced by high evaporation. Nat. Geosci., 4, 434-439, doi:10.1038/ngeo1174.

Guimberteau, M., K. Laval, A. Perrier, and J. Polcher, 2012: Global effect of irrigation and its impact on the onset of the Indian summer monsoon. Climate Dyn., 39, 1329-1348.

Haddeland, I., D. P. Lettenmaier, and T. Skaugen, 2006: Effects of irrigation on the water and energy balances of the Colorado and Mekong river basins. J. Hydrol., 324, 210-223.

Henderson-Sellers, A., and Coauthors, 1996: The Project for Intercomparison of Land-surface Parameterization Schemes (PILPS): 1992 to 1995. Climate Dyn., 12, 849-859.

Huffman, G. J., R. F. Adler, D. T. Bolvin, and G. Gu, 2009: Improving the global precipitation record: GPCP version 2.1. Geophys. Res. Lett., 36, L17808, doi:10.1029/2009GL040000.

Kueppers, L. M., M. A. Snyder, and L. C. Sloan, 2007: Irrigation cooling effect: Regional climate forcing by land-use change. Geophys. Res. Lett., 34, L03703, doi:10.1029/2006GL028679.

Lee, E., W. J. Sacks, T. N. Chase, and J. A. Foley, 2011: Simulated impacts of irrigation on the atmospheric circulation over Asia. J. Geophys. Res., 116, D08114, doi:10.1029/2010JD014740. 
Lobell, D. B., and C. Bonfils, 2008: The effect of irrigation on regional temperatures: A spatial and temporal analysis of trends in California, 1934-2002. J. Climate, 21, 2063-2071.

Mahfouf, J.-F., P. Viterbo, H. Douville, A. C. M. Beljaars, and S. Saarinen, 2000: A revised land-surface analysis scheme in the integrated forecasting system. ECMWF Newsletter, No. 88, ECMWF, Reading, United Kingdom, 8-13.

Mahmood, R., S. A. Foster, T. Keeling, K. G. Hubbard, C. Carlson, and R. Leeper, 2006: Impacts of irrigation on 20th century temperature in the northern Great Plains. Global Planet Change, 54, 1-18.

- , K. G. Hubbard, R. D. Leeper, and S. A. Foster, 2008: Increase in near-surface atmospheric moisture content due to land use changes: Evidence from the observed dewpoint temperature data. Mon. Wea. Rev., 136, 1554-1561.

Moore, N., and S. Rojstaczer, 2002: Irrigation's influence on precipitation: Texas High Plains, U.S.A. Geophys. Res. Lett., 29, 1755, doi:10.1029/2002GL014940.

Numaguti, A., 1999: Origin and recycling processes of precipitating water over the Eurasian continent: Experiments using an atmospheric general circulation model. J. Geophys. Res., 104 (D2), 1957-1972.

Ozdogan, M., M. Rodell, H. K. Beaudoing, and D. L. Toll, 2010: Simulating the effects of irrigation over the United States in a land surface model based on satellite-derived agricultural data. J. Hydrometeor., 11, 171-184.

Pielke, R. A., Sr., and X. Zeng, 1989: Influence on severe storm development of irrigated land. Natl. Wea. Dig., 14, 16-17.

- and Coauthors, 2011: Land use/land cover changes and climate: Modeling analysis and observational evidence. Wiley Interdiscip. Rev.: Climate Change, 2, 828-850, doi:10.1002/wcc.144.

Puma, M. J., and B. I. Cook, 2010: Effects of irrigation on global climate during the 20th century. J. Geophys. Res., 115, D16120, doi:10.1029/2010JD014122.

Reichle, R. H., and Coauthors, 2011: Assessment and enhancement of MERRA land surface hydrology estimates. J. Climate, 24, 6322-6338.

Rienecker, M. M., and Coauthors, 2011: MERRA: NASA's ModernEra Retrospective Analysis for Research and Applications. J. Climate, 24, 3624-3648.

Rodell, M., I. Velicogna, and J. S. Famiglietti, 2009: Satellite-based estimates of groundwater depletion in India. Nature, 460, 9991002, doi:10.1038/nature08238.

Sacks, W. J., B. I. Cook, N. Buenning, S. Levis, and J. H. Helkowski, 2009: Effects of global irrigation on the near-surface climate. Climate Dyn., 33,159-175, doi:10.1007/s00382-0080445-z.

Saeed, F., S. Hagemann, and D. Jacob, 2009: Impact of irrigation on the south Asian summer monsoon. Geophys. Res. Lett., 36, L20711, doi:10.1029/2009GL040625.

Segal, M., Z. Pan, R. W. Turner, and E. S. Takle, 1998: On the potential impact of irrigated areas in North America on summer rainfall caused by large-scale systems. J. Appl. Meteor., 37, 325-331.

Shiklomanov, I. A., 2000: Appraisal and assessment of world water resources. Water Int., 25, 11-32, doi:10.1080/02508060008686794.

Siebert, S., and Coauthors, 2005: Development and validation of the global map of irrigated areas. Hydrol. Earth Syst. Sci., 9, 535-547. , and Coauthors, cited 2007: Global map of irrigation areas version 4.0.1. Food and Agricultural Organization of the
United Nations, Rome, Italy. [Available online at http://www. fao.org/nr/water/aquastat/irrigationmap/index10.stm.]

Sodemann, H., C. Schwierz, and H. Wernli, 2008: Interannual variability of Greenland winter precipitation sources: Lagrangian moisture diagnostic and North Atlantic Oscillation influence. J. Geophys. Res., 113, D03107, doi:10.1029/2007JD008503.

Sorooshian, S., J. Li, K. Hsu, and X. Gao, 2011: How significant is the impact of irrigation on the local hydroclimate in California's Central Valley? Comparison of model results with ground and remote-sensing data. J. Geophys. Res., 116, D06102, doi:10.1029/2010JD014775.

Stohl, A., and P. James, 2004: A Lagrangian analysis of the atmospheric branch of the global water cycle. Part I: Method description, validation, and demonstration for the August 2002 flooding in central Europe. J. Hydrometeor., 5, 656-678.

Ter Maat, H. W., R. W. A. Hutjes, R. Ohba, H. Ueda, B. Bisselink, and T. Bauer, 2006: Meteorological impact assessment of possible large scale irrigation in southwest Saudi Arabia. Global Planet. Change, 54, 183-201.

Tuinenburg, O. A., R. W. A. Hutjes, and P. Kabat, 2012: The fate of evaporated water from the Ganges basin. J. Geophys. Res., 117, D01107, doi:10.1029/2011JD016221.

van der Ent, R. J., H. H. G. Savenije, B. Schaefli, and S. C. SteeleDunne, 2010: Origin and fate of atmospheric moisture over continents. Water Resour. Res., 46, W09525, doi:10.1029/ 2010WR009127.

Vörösmarty, C. J., and Coauthors, 1998: Potential evaporation functions compared on US watersheds: Possible implications for global-scale water balance and terrestrial ecosystem modeling. J. Hydrol., 207, 147-169.

Wada, Y., L. P. H. van Beek, C. M. van Kempen, J. W. T. M. Reckman, S. Vasak, and M. F. P. Bierkens, 2010: Global depletion of groundwater resources. Geophys. Res. Lett., 37, L20402, doi:10.1029/2010GL044571.

Wei, J., and P. A. Dirmeyer, 2012: Dissecting soil moistureprecipitation coupling. Geophys. Res. Lett., 39, L19711, doi:10.1029/2012GL053038.

- — - Z. Guo, L. Zhang, and V. Misra, 2010: How much do different land models matter for climate simulation? Part I: Climatology and variability. J. Climate, 23, 3120-3134.

- _ - M. G. Bosilovich, and R. Wu, 2012: Water vapor sources for Yangtze River valley rainfall: Climatology, variability, and implications for rainfall forecasting. J. Geophys. Res., 117, D05126, doi:10.1029/2011JD016902.

Wisser, D., S. Frolking, E. M. Douglas, B. M. Fekete, C. J. Vörösmarty, and A. H. Schumann, 2008: Global irrigation water demand: Variability and uncertainties arising from agricultural and climate data sets. Geophys. Res. Lett., 35, L24408, doi:10.1029/2008GL035296.

, B. M. Fekete, C. J. Vörösmarty, and A. H. Schumann, 2010: Reconstructing 20th century global hydrography: A contribution to the Global Terrestrial Network-Hydrology (GTN-H). Hydrol. Earth Syst. Sci., 14, 1-24.

Xie, P., J. E. Janowiak, P. A. Arkin, R. Adler, A. Gruber, R. Ferraro, G. J. Huffman, and S. Curtis, 2003: GPCP pentad precipitation analyses: An experimental dataset based on gauge observations and satellite estimates. J. Climate, 16, 2197-2214.

, A. Yatagai, M. Chen, T. Hayasaka, Y. Fukushima, C. Liu, and S. Yang, 2007: A gauge-based analysis of daily precipitation over East Asia. J. Hydrometeor., 8, 607-627. 